\title{
OSMAN LINS E AS ILUSTRAÇÕES DOS LIVROS, "UM CHAMADO INFERNAL": AS IMAGENS AINDA/JÁ CHEIAS DE PALAVRAS
}

\section{Ana Luiza Andrade*}

\begin{abstract}
Resumo: Ao viver em uma época em que começam a se tornar comuns as publicações de séries industriais, Osman Lins, em duas de suas crônicas inéditas trazidas à tona no presente estudo, chama a atenção sobre a transposição de uma ficção escrita para uma ficção imagética. Versando sobre o desenho do ilustrador e o texto feito de palavras, "Romance e desenho" (Jornal do Commercio, 23/ago/1959) e "Reflexão sobre um livro de contos" (Jornal do Commercio, 11/out/1959), estes refletem respectivamente uma preocupação por si mesma incomum, pois, ao enfocar uma etapa técnica que rapidamente passou, e que se fixava nas capas de ilustradores significativos para a história das edições de romances (aqui, em particular sobre a edição de Moby Dick de Melville e as suas séries), além da rara qualidade artística de suas capas e de suas ilustrações, Osman Lins abria, com isso, uma brecha na crítica que, até então, se dirigia, exclusivamente, ou para a literatura ou para a imagem. Mas nunca como uma poderia diminuir ou acrescentar à outra. O mesmo seria verdade quando se pensa na passagem da imagem romanesca transposta para a cinemática.
\end{abstract}

Palavras-chave: Osman Lins. Ilustrações. Imagem-palavra.

Atribuirmos dinamismo a uma ilustração parecerá talvez uma fantasia. Mas a ilustração feliz, a que contribui para um prolongamento ou ressonância do livro, é como que vivificada, tocada pelo texto, que a ela se une em nosso espírito, onde o caráter estático das figuras perde a rigidez e se anima num sentido criador.

Osman Lins, Romance e Desenho, 1959.

O autor como veiculador de outros meios de produção na era da reprodutibilidade técnica transparece nos escritos de Osman Lins ${ }^{1}$. Por tanto se interessar pela passagem da palavra à imagem na modernidade, este autor se caracteriza como alguém que não era somente consciente de viver em uma época em que começam a se tornar comuns as séries industriais, mas também por sentir-se na obrigação de conscientizar os outros disso. Ao mesmo tempo, este fato reflete, principalmente, a sua preocupação com a venda mercadológica da palavra escrita ou mesmo, sua trivialização, nos novos meios de produção que nestes anos alternavam indiscriminadamente palavra e imagem, e assim começavam a circular mais frequentemente no mercado. No entanto, esta preocupação era por si mesma incomum. Ao enfocar uma etapa técnica que rapidamente passou, e que se fixava nas capas de ilustradores significativos para a história das

\footnotetext{
* Doutora em Literatura Luso Brasileira e Hispano Americana pela University of Texas at Austin. Professora de Literatura Brasileira na graduação e no Programa de Pós-graduação em Literatura (UFSC). E-mail: andradeufsc@gmail.com.

${ }^{1}$ Osman Lins foi autor-produtor quando refuncionaliza seus meios de produção: escritor de romances, dramaturgo, escritor de livros infantis, roteirista de televisão, resenhista, contista e cronista. Ler sobre o "Autor como produtor" em Walter Benjamin, Magia e técnica, arte e política, Obras Escolhidas I, trad. Sergio Paulo Rouanet, Prefacio Jeanne Marie Gagnebin. São Paulo: Brasiliense, 1994.
} 
edições de romances que refletiam a rara qualidade artística de suas capas e de suas ilustrações, Osman Lins abria, com isso, uma brecha na crítica que, até então, se dirigia, exclusivamente, ou para a literatura ou para a imagem. Mas nunca como uma poderia diminuir ou acrescentar à outra. $\mathrm{O}$ mesmo seria verdade quando se pensa na passagem da imagem romanesca para a cinemática.

Duas de suas crônicas inéditas ${ }^{2}$ sobre o desenho do ilustrador e o texto feito de palavras, "Romance e desenho" (Jornal do Commercio, 23/ago/1959) e "Reflexão sobre um livro de contos" (Jornal do Commercio, 11/out/1959) chamam a atenção sobre a preocupação do autor com a transposição de uma ficção escrita para uma ficção imagética. Na primeira crônica, o autor se refere não só ao problema de refuncionalizar (como diria Benjamin) determinado romance em filme, mas também no que concerne a uma segunda operação de refuncionalização: tentar passar a imagem interior formada no leitor através da impressão imaginária causada por um determinado personagem de romance para o papel. Ou seja, a novidade estaria em perceber criticamente a visão de um personagem através de uma leitura das ilustrações de determinadas edições que apareciam nas capas e nas imagens dos livros, visão esta que já havia deixado na imaginação do leitor uma determinada impressão cinematográfica ao ter se tornado pública pelo filme que tinha sido "adaptado" a partir do romance ${ }^{3}$. Assim inicia Osman Lins o seu artigo "Romance e desenho":

\begin{abstract}
Talvez não seja indignação - mas apenas tristeza - o que me desperta a filmagem de romances como Madame Bovary e Uma tragédia americana. ${ }^{4}$ E não quero referir-me ao debatidíssimo problema da confusão gerada no espírito de certos indivíduos que julgam haver possuído o livro, pelo fato de haverem assistido o filme, deslembrados de que aquele é feito com palavras, enquanto que na película cinematográfica tudo ou quase tudo nos é transmitido pela imagem e quem, em geral, a substância mais profunda do livro, à qual só chegamos pela meditação, é inalcançável pelo cinema, cuja própria natureza não lhe permite transmiti-la. Aqui, o que me impressiona é um outro problema: o da limitação ou fixação do personagem no sentido material. (negrito do autor)
\end{abstract}

Osman Lins considera uma limitação esta fixação do personagem; ou seja, para ele, ela era redutora:

\footnotetext{
2 Estas crônicas foram encontradas por Cristiano Moreira, pesquisador do Núcleo de Estudos Benjaminianos (NEBEN), no Arquivo da Fundação Joaquim Nabuco, em Recife, e digitalizadas por Sidney Borges, bolsista PIBIC do NEBEN. Sua divulgação se faz como uma homenagem aos 90 anos de Osman Lins, comemorada em 2014.

3 A palavra "adaptação" é comumente usada para significar a tradução do meio de produção do romance para o meio de produção do cinema. No entanto, optamos por utilizar o termo "refuncionalização", que significa colocar para funcionar novamente por outro meio... que é mais de acordo com o conceito benjaminiano. In: Walter Benjamin, "O autor-produtor", in: Magia e técnica, arte e política. Obras Escolhidas I, tradução Sergio Paulo Rouanet, prefácio Jeanne Marie Gagebin. São Paulo: Brasiliense, 1994.

${ }^{4}$ Madame Bovary se refere ao romance conhecido de Flaubert. Já Tragédia Americana, de Theodore Dreiser (1871-1945), é mais familiar a um público leitor norte-americano. O primeiro sucesso comercial de Dreiser, Uma Tragédia Americana (1925), é a história de um jovem de caráter instável surpreendido por acontecimentos que o levam à execução por assassinato. O romance deu origem a um filme em $1931 \mathrm{e}$ novamente em 1951.
} 
Muitos não verão o mínimo inconveniente e acharão talvez que o romance exige do leitor um esforço imaginativo, incomum, e que este esforço é reduzido e facilitado pelos elementos visuais que o cinema pode trazer. Acho, no entanto, que esta facilidade é perniciosa, pois constitui um empobrecimento.

Mas em seguida, ao apontar a singularidade e a multiplicidade do personagem do romance, vai exemplificar através de personagens tais quais Julien Sorel de Stendhal e aquele que chama de "soturno gentleman de Vitoria" de Conrad, essa complexidade de caráter que não pode ser fixada em uma imagem determinada. Interessante ele ter usado o aposto "soturno gentleman de Vitoria" no lugar do nome, como se este já fixasse, de algum modo, esta imagem. ${ }^{5}$ Isto porque Osman Lins explica, através de outros exemplos, o que queria dizer esse "empobrecimento" ou essa redução do personagem, ao dizer que depois de assistir Um lugar ao sol ${ }^{6}$ não é mais possível separar o ator de Hollywood, Montgomery Clift, do personagem de Dreiser (Clyde Griffiths), nas palavras de Osman Lins "ficando assim reduzido a um denominador comum "made in Hollywood' o grande personagem de Dreiser." Pode-se então perceber este início de redução imaginativa que esta publicidade da imagem do ator acarretava.

No entanto, ele acreditava que se um preconceito contra a refuncionalização do romance para o cinema continuava em vigor até então (e poderíamos acrescentar, até hoje), chega também ao reconhecimento de que aquele preconceito contra a ilustração do romance tinha acabado, ao explicar:

\begin{abstract}
É que víamos, na ilustração do romance, um auxílio, uma imposição, uma restrição e nunca um enriquecimento - este bem diverso do que o cinema em vão pretendia trazer. E não apreendíamos, o que é bem mais grave, duas coisas importantes: $1^{\mathrm{a}}$. O caráter dinâmico da boa ilustração; $2^{\mathrm{a}}$. Sua faculdade de nos predispor a sentir e a compor, mesmo antes de iniciada a leitura, a atmosfera do romance.
\end{abstract}

Pesquisador incansável nesta temática que o apaixonava, Osman Lins passa a arrolar os nomes de alguns ilustradores de livros que se tornaram famosos nesta época em que eram prestigiados através da produção das capas e das ilustrações dos romances, imagens sobre suas cenas marcantes: dentre eles Percy Lau ${ }^{7}$, Oswaldo Goeldi ${ }^{8}$, Axl Leskoschek $^{9}$, Poty ${ }^{10}$, Santa Rosa ${ }^{11}$, Rockwell Kent ${ }^{12}$.

\footnotetext{
5 Vitoria foi escrito em 1915 por Joseph Conrad (1857-1924). Com as ilhas exóticas do Arquipélago Malaio como cenário, esta história de traição e de isolamento de Conrad tem no seu centro uma celebração da lealdade e do poder sublime do amor. Quando o solitário Axel Heyst foge com uma jovem que mal conhece, os ciúmes e as suspeitas da comunidade local entram em ebulição, como o vulcão que todos ensombra.

${ }^{6}$ Um lugar ao sol, filme norte-americano de 1951, um drama, atuado por Montgomery Clift e Elizabeth Taylor, realizado por George Stevens e com roteiro baseado em livro de Theodore Dreiser.

${ }^{7}$ Percy Lau (Arequipa, Peru 1903 - Rio de Janeiro RJ 1972). Desenhista, ilustrador, gravador e pintor. Em 1921, transfere-se para Olinda, Pernambuco. Durante 30 anos, é ilustrador do Instituto Brasileiro de Geografia e Estatística (IBGE), que reedita Tipos e Aspectos do Brasil (1960), baseando-se em textos da Revista Brasileira de Geografia, com desenhos do artista. Cria ilustrações para os livros Arraial do Tijuco, de Aires da Mata Machado; E Eles Verão a Deus - o Drama do Aleijadinho, de Kurt Pahlen; Santa Maria do Belém do Grão Pará, de Leandro Tocantins; Vila dos Confins, de Mário Palmério; Guia Histórico e Sentimental de São Luís do Maranhão, de Astolfo Serra; e Maxabombas e
} 
Maracatus, de Mário Sette, entre outros. Tanto no trabalho de ilustração, como no desenho e na gravura, Percy Lau destaca-se por registrar os aspectos físicos e humanos do Brasil. Em 1953, recebe medalha de prata no $2^{\circ}$ Salão Nacional de Arte Moderna, no Rio de Janeiro. Dez anos depois, é premiado como melhor ilustrador pela Câmara Brasileira do Livro. Em 2000, o Museu Nacional de Belas Artes (MNBA) promove a exposição Percy Lau: um Desenhista e seu Traço. (In Enciclopedia Itaú Cultural, enciclopedia.itaucultural.org.br).

${ }^{8}$ Nascido no Rio de Janeiro, em 1895, Oswaldo Goeldi foi ilustrador, desenhista e professor. Sua primeira exposição individual aconteceu no ano de 1917 em Berna, atual capital da Suíça, onde o ilustrador conheceu Alfred Kubin, artista que influenciou significativamente sua obra. Ao longo de sua vida, Goeldi ilustrou livros, revistas, periódicos e trabalhou com xilogravuras. Entre os livros que ilustrou, encontram-se Mar morto e Navegação de cabotagem, do escritor Jorge Amado. Faleceu em 16 de fevereiro de 1961. (In: Ilustradores, Casa de Jorge Amado: www.jorgeamado.com.org).

${ }^{9}$ Axl von Leskoschek (Graz, Áustria 1889 - Viena, Áustria 1975). Gravador, pintor, ilustrador, desenhista, professor, cenógrafo. Ingressa na Escola de Belas Artes de Graz e na Escola de Artes Gráficas de Viena, em 1919, e tem aulas com Hofbauer, Hermann Cossmann (1884 - 1966) e Schorotter. Fugindo do nazismo, refugia-se na Suíça, onde inicia a série de xilogravuras de Odysséia. Em 1939, muda-se para o Rio de Janeiro e leciona xilogravura no curso de desenho de propaganda e de artes gráficas da Fundação Getúlio Vargas - FGV, entre seus alunos estão Fayga Ostrower (1920 - 2001), Renina Katz (1926), Ivan Serpa (1923 - 1973) e Edith Behring (1916 - 1996), e também dá aulas de gravura em seu ateliê, no bairro da Glória. O artista, além de realizar xilogravuras, pinta paisagens, naturezas-mortas e cenas do cotidiano carioca e fluminense. Ilustra vários livros, a maioria publicada pela Livraria Editora José Olympio, como O Romanceiro do Brasil, de Ulrich Bechers, Dois Dedos, de Graciliano Ramos (1892 - 1953), Uma Luz Pequenina, de Carlos Lacerda, e as traduções brasileiras de Fédor Dostoïevski (1821 - 1881). Retorna à Áustria em 1949, e ilustra revistas e livros. (In: Enciclopedia Itaú Cultural, enciclopedia.itaucultural.org.br).

${ }^{10}$ Napoleon Potyguara Lazzarotto (Curitiba-PR, 1924 - idem, 1998), apelidado Poty. Gravador, desenhista, ilustrador, muralista e professor. Muda-se para o Rio de Janeiro em 1942 e estuda pintura na Escola Nacional de Belas Artes (Enba). Frequenta curso de gravura com Carlos Oswald (18821971) no Liceu de Artes e Ofícios do Rio de Janeiro. Em 1946, viaja para Paris, onde permanece por um ano. Estuda litografia na École Supérieure des Beaux-Arts, com bolsa do governo francês. Em 1950, funda, juntamente com Flávio Motta (1916), a Escola Livre de Artes Plásticas, na qual leciona desenho e gravura. Nessa época organiza o primeiro curso de gravura do Museu de Arte de São Paulo Assis Chateaubriand (Masp). Organiza, ao longo da década de 1950, cursos sobre gravura em Curitiba, Salvador e Recife. Desde os anos 1960, tem destaque como muralista, com diversas obras em edifícios públicos e particulares no país e no exterior. Tem relevante atuação como ilustrador de obras literárias como as de Jorge Amado, Graciliano Ramos, Euclides da Cunha e Dalton Trevisan, entre outros. É autor dos livros A Propósito de Figurinhas, de 1986, e Curitiba, de Nós, de 1989, em parceria com Valêncio Xavier Niculitcheff. Executa diversos murais, como o da Casa do Brasil, em Paris, 1950, e o painel para o Memorial da América Latina, São Paulo, 1988. A partir dos anos 1980 são lançadas várias publicações sobre sua produção, entre elas: Poty Ilustrador, de Antônio Houaiss (1915-1999), em 1988; Poty: Trilhos, Trilhas e Traços, de Valêncio Xavier Niculitcheff, em 1994; e Poty: o lirismo dos anos 90, de Regina Casillo, em 2000. (In: Enciclopedia Itaú Cultural, enciclopedia.itaucultural.org.br).

${ }^{11}$ Tomás Santa Rosa, mais conhecido como Santa Rosa, nasceu em João Pessoa (PB), no ano de 1909. Ainda jovem, iniciou sua carreira como contador, trabalhando no Banco do Brasil. Nesse período, foi transferido para Salvador e, posteriormente, para Maceió (AL), onde se envolveu com o movimento intelectual local. Não possuía formação artística acadêmica, era autodidata. Nos anos trinta, mudou-se para o Rio de Janeiro. Ficou conhecido por seus trabalhos na cenografia teatral, fazendo criações para a Cia. de Comédias Jaime Costa, e pela criação posterior do seu próprio grupo de teatro, Os Comediantes, sendo considerado o primeiro cenógrafo moderno brasileiro. Fundou o Jornal A Manhã, em que ilustrava e escrevia periódicos relacionados às Letras e às Artes. Por um período, foi responsável pela área de teatro do Museu de Arte Moderna do Rio de Janeiro, onde posteriormente lecionou desenho estrutural. Iniciou seus trabalhos como ilustrador de obras pela Editora José Olympio. Nesta função, ficou conhecido por confeccionar não apenas ilustrações para os livros, mas projetos gráficos completos. Ilustrou trabalhos de grandes escritores, como Graciliano Ramos, José Lins do Rego, Rachel de Queiroz e Carlos Drummond de Andrade. Para Jorge Amado, ilustrou Cacau, ABC de Castro Alves e Navegação de cabotagem. Atua também na pintura, ajudando o pintor Cândido Portinari na criação de diversos murais. Em viagem à Índia representando o Brasil, sofre morte repentina, vindo a falecer aos 47 anos de idade. A 
No segundo artigo aqui mencionado, "Reflexão sobre um livro de contos", escrito para o Jornal do Commercio, Osman Lins resenha o livro de Jorge Rizzini, uma coletânea de contos intitulada Beco dos Aflitos. Desde o início, o leitor percebe que ao resenhador interessou mais a adequação do desenho da capa do livro, por Walter Lewy $^{13}$, à matéria dos contos do que eles próprios. Por isso a sua descrição desta capa é longa:

carreira de Santa Rosa resume-se a trabalhos em diversos ramos como: pintura, cenografia, ilustração, artes gráficas, gravura, docência, decoração, figurino e crítica de arte. "Com ilustrações de Santa Rosa, as primeiras do desenhista que revolucionou as capas e as ilustrações dos livros brasileiros, Cacau esgotou em quarenta dias a edição de dois mil exemplares: a proibição de venda por subversivo, decretada pela polícia carioca, ajudou o sucesso de público.” Jorge Amado (In: Ilustradores, Casa de Jorge Amado: www.jorgeamado.com.org).

${ }^{12}$ Rockwell Kent (21 de Junho de 1882 - 13 de março de 1971) foi um pintor, um printmaker, ilustrador e escritor. Rockwell Kent nasceu em Tarrytown, New York, no mesmo ano que outros artistas norteamericanos tais como George Bellows e Edward Hopper. Kent viveu boa parte de sua infância em torno de Nova York, onde ele frequentou a Escola Horace Mann. Em meados de seus 40 anos, ele se mudou para uma fazenda Adirondack, que ele chamou Asgaard, onde ele viveu e pintou até sua morte. Kent estudou com vários pintores e teóricos influentes de sua época. Estudou composição e design com Arthur Wesley Dow na Art Students League, no outono de 1900, e estudou pintura com William Merritt Chase nos três verões entre 1900 e 1902, depois ele entrou, no outono de 1902, para o curso oferecido por Robert Henri na Escola de Arte de Nova York, que Chase havia fundado. Durante o verão de 1903, em Dublin, New Hampshire, Kent foi aprendiz do pintor e naturalista Abbott Handerson Thayer. Um fundo de graduação em arquitetura na Universidade de Columbia preparou Kent para o trabalho diversificado, entre 1900 e 1910, tanto de um representante de arquitetura como de carpinteiro. No Art Students League, ele iria se encontrar e fazer amizade com os artistas Wilhelmina Weber Furlong e Thomas Furlong. As primeiras pinturas de Kent de Mount Monadnock e New Hampshire foram expostas pela primeira vez na Sociedade dos Artistas norte-americanos em Nova York, em 1904, quando Dublin Pond foi comprada pelo Smith College. Em 1905, Kent aventurou-se a Monhegan Island, Maine, e encontrou sua beleza acidentada e primordial, uma fonte de inspiração para os próximos cinco anos. Sua primeira série de pinturas de Monhegan foram expostas causando a grande aclamação da crítica em 1907 nas Galerias Clausen em Nova York. Essas obras formam a base de sua reputação duradoura como um americano modernista avant la lettre. Abordado em 1926 pela editora RR Donnelley para produzir uma edição ilustrada de Richard Henry Dana, Jr., Kent sugeriu Moby Dick de Melville em seu lugar. Publicado em 1930 pela Lakeside Press de Chicago, os três volumes da edição limitada com desenhos em preto e branco a caneta / pincel e tinta esgotou rapidamente; Random House produziu uma edição comercial, que também foi imensamente popular. Um livro anteriormente obscuro, Moby Dick tinha sido redescoberto pelos críticos no início de 1920. O sucesso da edição de Rockwell Kent ilustrada foi um fator que contribuiu para torná-lo cada vez mais reconhecido como o clássico que é hoje. (Wikipedia e http://finslab.com/enciclopedia/letra-r/rockwell-kent.php).

${ }^{13}$ Walter Lewy (Bad Oldesloe, Alemanha, 1905 - São Paulo-SP, 1995) Gravador, pintor, ilustrador, paisagista, desenhista e publicitário. Estuda na Escola de Artes e Ofícios de Dortmund, Alemanha, entre 1923 e 1927. Nesse período, filia-se à tendência do realismo mágico. Já em 1928, participa de coletivas em Dortmund, Gelsenkirchen, Boclusim e outras cidades. Com a crise econômica de 1929, Lewy perde seu emprego de desenhista numa gráfica e vai viver com os pais no interior, tornando-se ilustrador de anedotas em jornais. Realiza sua primeira exposição individual em Bad Lippspringe em 1932, mas ela é fechada quando a Câmara de Arte Alemã proíbe a participação de judeus na vida artística. Escapando dessa situação opressora, o artista imigra para o Brasil em 1938, retomando profissionalmente a pintura. Deixa para trás centenas de trabalhos, que são enviados para a Holanda e perdidos durante os bombardeios da Segunda Guerra Mundial (1939-1945). No Brasil, fixa-se em São Paulo. Nos primeiros anos, faz desenho publicitário e mais tarde capas de livros e ilustrações para diversas editoras. Ilustra obras de Bertrand Russell, Machado de Assis e Arnold Toynbee, entre outras. Mais tarde, emprega-se como diagramador, letrista e arte-finalista nas agências de propaganda De Carli, Lintas Publicidade, Martinelli, Santos \& Santos e Thompson Propaganda. 
A capa do BECO DOS AFLITOS foi desenhada pelo Sr. Walter Lewy, em cinza, rubro e negro, com as letras brancas. Não sei se houve, na concepção da mesma, uma intenção simbólica, ou se buscou o desenhista um resultado puramente plástico. De qualquer modo, conscientemente ou não, acredito que os contos induziram o autor da capa na escolha do cinzento, do negro e do vermelho, escolha demasiado significativa para ser casual. Nenhum verde marinho ou vegetal, nenhum azul matinal, nem mesmo as equívocas atenuações do amarelo, seriam concebíveis em livro tão amargo. Tem-se mesmo a impressão de que, nos meses em que o Sr. Jorge Rizzini se entregou, silenciosamente, à composição desses contos, perdera por completo o dom dos entretons, bem como a faculdade de ver objetos alegres, ou ainda outros que não o sendo, existissem fora dessa como tirania cromática que parece havê-lo obcecado, imaginando sempre as suas criaturas, o íntimo de suas criaturas e o mundo no qual elas bracejam, eternamente negros, cinzentos e sanguíneos.

Traz o livro, como epígrafes, citações de Hermann Hesse e Dostoiévski, o que talvez possa servir de indício para uma tentativa de indagação. Teria sucedido ao Sr. Jorge Rizzini, em certo propício momento de sua vida, o simultâneo encontro daqueles romancistas, ou melhor, a confluência de Dostoiévski e do Lobo da Estepe, já que é o clima alucinatório deste que parece preponderar nos contos do BECO DOS AFLITOS, onde em nenhuma página reponta o outro Hermann Hesse, o Hesse, senão pacificado, pelo menos domado e clarificado de, por ex., "Narciso e Goldmundo". Terá havido essa coincidência, essa convergência violenta, pesada demais para o Sr. Jorge Rizzini, cujo espírito - quem sabe por que - se fizera vulnerável, gerando esses contos escuros, cuja substância, estranhamente se desentende da linguagem?

Se o primeiro parágrafo descreve uma "tirania cromática" que parece ter obcecado o autor, o segundo descreve o "clima alucinatório" de certos autores como Hesse e Dostoievski, que prepondera nos contos do Sr. Rizzini. No entanto, é a escuridão dos contos (um "mundo negro, cinzento e sanguíneo", nas palavras aproximadas de Osman Lins) que impressiona, e esta é captada pelo ilustrador.

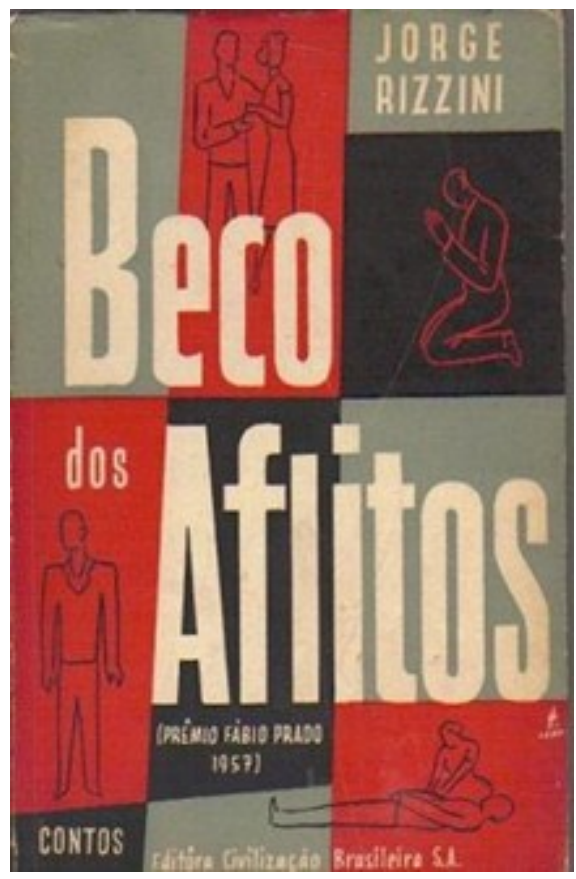

Figura 1 - Capa de "Beco dos Aflitos". 
Percebe-se, então, que um dos pontos em comum entre alguns destes ilustradores é o de terem sido perseguidos políticos do nazismo por serem judeus ou por terem se filiado, em algum ponto de suas vidas, ao Partido Comunista. Ou, pelo menos, o fato de serem judeus é tanto o caso de Axl von Leskoschek, que se muda para o Rio de Janeiro em 1939, fugindo do nazismo, como também o de Walter Lewy, que imigra também para o Rio em 1938. O de ter sido comunista é o caso de Rockwell Kent, que também veio ao Brasil em $1937^{14}$.

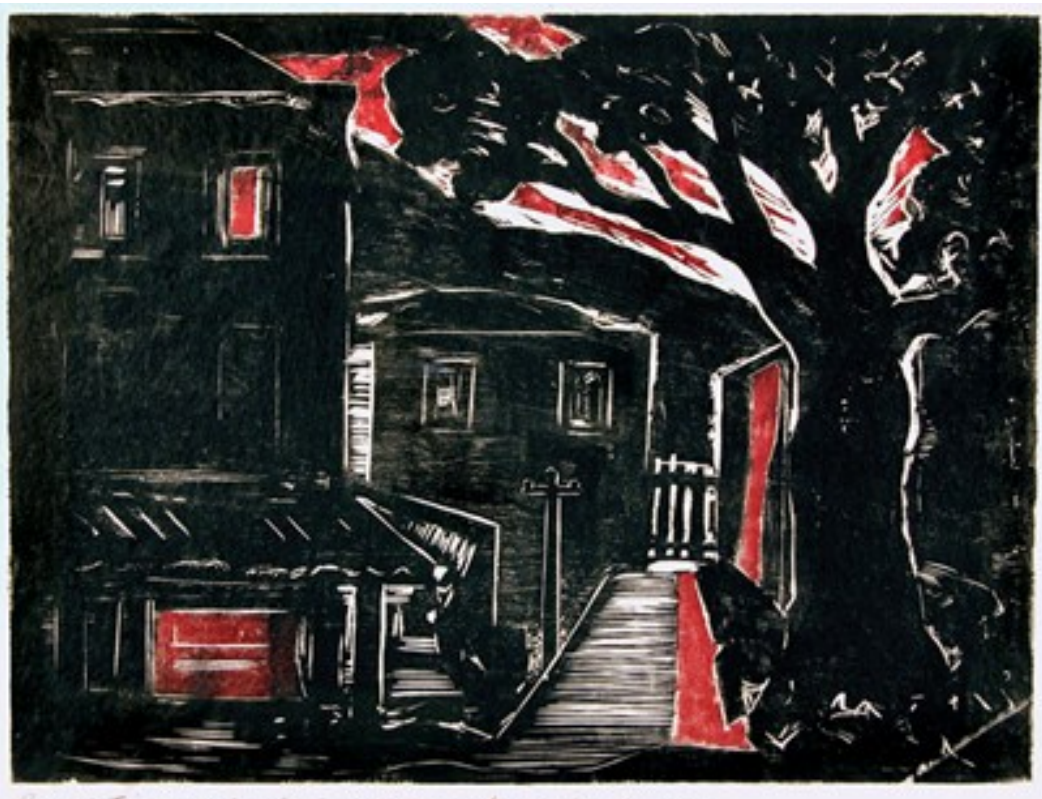

Figura 2 - Oswaldo Goeldi, Céu Vermelho, xilogragura, 1950.

Já Oswaldo Goeldi, cujo pai era o famoso cientista suíço Emilio Goeldi, que fundou o Museu Goeldi em Belém do Pará, se tornou um gravurista famoso pela criação de imagens urbanas onde há, como no Lewy da capa de Beco dos Aflitos, uma atmosfera de angústia, senão de uma solidão profunda. Nas gravuras de Goeldi, figuras humanas se perdem em ruas, becos e praças mal iluminadas de cidades indiferentes à presença de cada um. Há também em suas gravuras uma atmosfera dominada pelo escuro, só

\footnotetext{
${ }^{14} \mathrm{O}$ ilustrador Rockwell Kent era também um militante político contra o avanço do fascismo e a iminente guerra. Filia-se ao Partido Comunista em 1936. Vem ao Brasil no mês de junho como presidente do Comitê Nacional pelos Direitos do Povo e encarregado, com Jerome Davis, de serem observadores políticos, tanto a serviço do comitê, quanto do Comitê Unido pela Defesa do Povo Brasileiro. O embaixador brasileiro em Washington, Oswaldo Aranha, concede carta de apresentação à Rockwell para uma viagem de nove dias ao Rio de Janeiro. A viagem possui objetivos bastante claros: localizar o paradeiro do prisioneiro político de Vargas, Luís Carlos Prestes, ocorrido um pouco antes do golpe de Estado, observar o avanço do Fascismo, promovido por ditadores no Hemisfério Sul, "através das crescentes supressões governamentais das liberdades civis e das prisões arbitrárias de seus líderes oposicionistas... impostos ao povo do Brasil", e estabelecer contato com todos aqueles que se opõem ao ditador. Todas as informações sobre o ilustrador a respeito de sua vida política e seus contatos com o Brasil se devem à dissertação de mestrado de Karin Phillipov, apresentada ao Departamento de História do Instituto de Ciências Humanas da Universidade Estadual de Campinas, sob a orientação de Jorge Coli, intitulada "Rockwell Kent e o Brasil", dezembro de 2008. A dissertação de mestrado se encontra integralmente acessível por internet.
} 
rompido pela luz branca filtrada ou por pequenas superfícies de cor. Em seu imaginário, pescadores, peixes e o mar protagonizam cenas que denotam uma solidão profunda. Suas xilogravuras são emblemáticas do conflito do ser humano e uma das melhores tradições da arte brasileira. Os trabalhos de Goeldi estão frequentemente em exposição em São Paulo nas últimas décadas, o que reflete a sua importância para a história da arte paulista. Coincidentemente, (figura 2) Goeldi segue esta mesma "tirania" cromática" de um "mundo negro, cinzento e sanguíneo" observada no Lewy do Beco dos Aflitos:

O caso de Rockwell Kent também é especial, pois ele chegou a vir ao Brasil e a travar amizade com Portinari, que faz o seu retrato e, em troca, o ilustrador norteamericano escreve a primeira biografia estrangeira do artista brasileiro: Portinari his life and art (1940), incorporando algumas palavras de Dostoievski que já tinha usado para a capa do catálogo da exposição na galeria Knoedler, no Alaska, a este livro sobre Portinari.
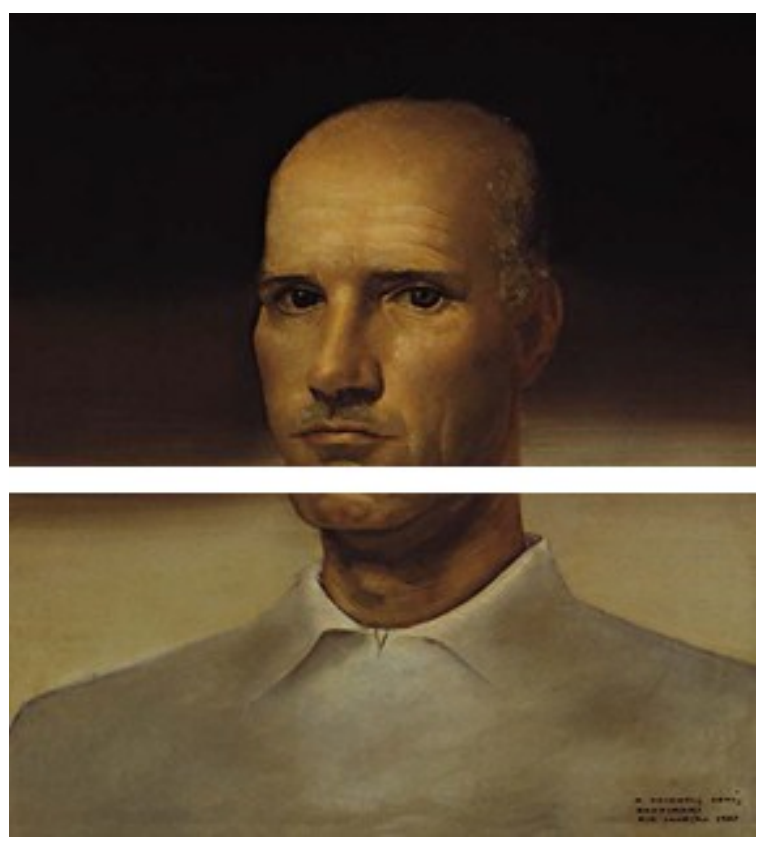

Figura 3 - Retrato de Rockwell Kent.

Acima, o retrato de Rockwell Kent por Cândido Portinari, tela a óleo de 1937 dedicada ao ilustrador, com quem trava intensa correspondência de 1938 a 1940, também para tratar da Exposição no Pavilhão Brasileiro da Feira Mundial (1937).

Rockwell chega a acusar o regime de Vargas por seu caráter fascista e ditatorial em seu relatório de 1938, "Brazil and Vargas", mas muda de opinião em It's Me O Lord, livro publicado em 1955, no qual afirma que o Brasil não vive sob os ditames do Fascismo, contrariando a opinião norte-americana de que o Fascismo controla o Brasil. Vira-se, nesta ocasião, contra o seu próprio país, julgando-o fascista. Na ilustração acima, uma alegoria política, a sua posição de resistência aos regimes que aprisionam as oposições ao poder na América Latina (foi a favor da independência de Porto Rico dos Estados Unidos) pode ser detectada: há um representante do povo aprisionado em uma mão que o controla (com a conhecida visão do morro do Corcovado no fundo) visto 
contra a paisagem carioca, capital brasileira naquele então. Esta mão lembra, inclusive, a mão esculpida no projeto de Oscar Niemeyer, inspirado no livro de Eduardo Galeano, As veias abertas da América Latina (1971), e que foi inaugurado com o Memorial da América Latina em São Paulo, em 1989. No entanto, o caráter de denúncia das ilustrações de Rockwell é forte. Ele ilustra a imagem da capa da brochura escrita por Harrison Jorge, "It happened in Brazil" (uma provável alusão ao filho de Harrison Jorge Victor Allan Barron, assassinado pela polícia secreta de Vargas no ano anterior à vinda de Rockwell e de Harrison Jorge? $)^{15}$, uma figura no ar, transpassada por uma espada. Não surpreende o fato de Karin Phillipov comparar o conhecido quadro de David, $A$ Morte de Marat, à cena violenta de Rockwell Kent.

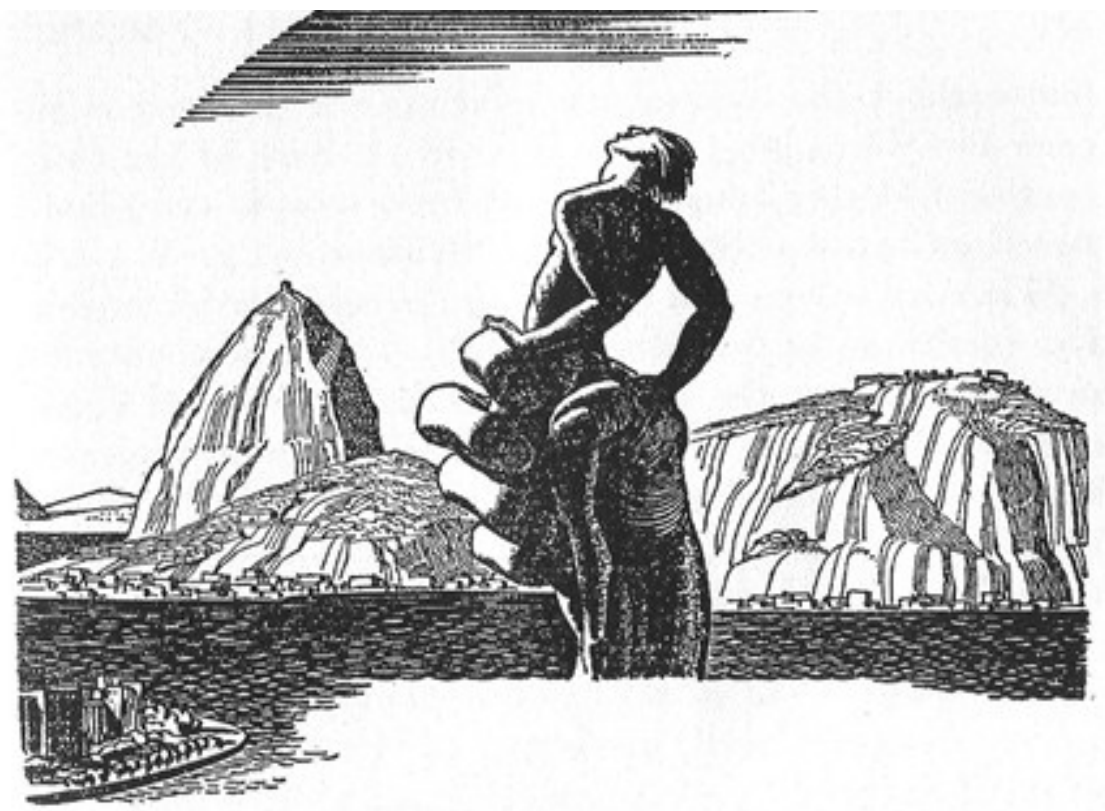

Figura 4 - Ilustração de This is My Own, para o capítulo "A Friendly Neighbor" (Um Vizinho Amigável), 1940.

Por se tratar de matéria de muito fôlego e para muito mais análise, atenho-me aqui apenas a algum dos aspectos de um desses ilustradores mencionados por Osman Lins: Rockwell Kent, artista nem sempre conhecido dos brasileiros, apesar de seus contatos com o nosso país. Interessa, aqui, principalmente, tanto o enfoque na capa dos livros, como esta conexão política de Rockwell Kent, principalmente pelo interesse osmaniano que, evidentemente, sentiu-se atraído por estar tão próxima do tema do artista ou do escritor que escreve sob a opressão política ditatorial no Brasil, como fica explícito em vários de seus textos, a exemplo de Avalovara e Rainha dos Cárceres da Grécia. Também o clima angustiado desses ilustradores, assim como em Goeldi, Lewy, além de Rockwell Kent, parece contribuir para a opressão que o romancista conseguiu transmitir em seus escritos sob o regime ditatorial militar entre os anos de 1964 e 1978, quando

\footnotetext{
${ }^{15}$ Dissertação de mestrado de Karin Phillipov, apresentada ao Departamento de História do Instituto de Ciências Humanas da Universidade Estadual de Campinas, sob a orientação de Jorge Coli, intitulada Rockwell Kent e o Brasil, dezembro de 2008, p.182.
} 
morre. Osman Lins conseguiu, pela editora Melhoramentos, toda a sua obra de ficção reeditada com ilustrações de Kelio Rodrigues ${ }^{16}$, um ilustrador sui generis que procurou mostrar através de capas realmente ilustrativas dos conteúdos ficcionais com um certo caráter surrealista, uma visão singular destes livros. A capa de Avalovara é sugestiva:

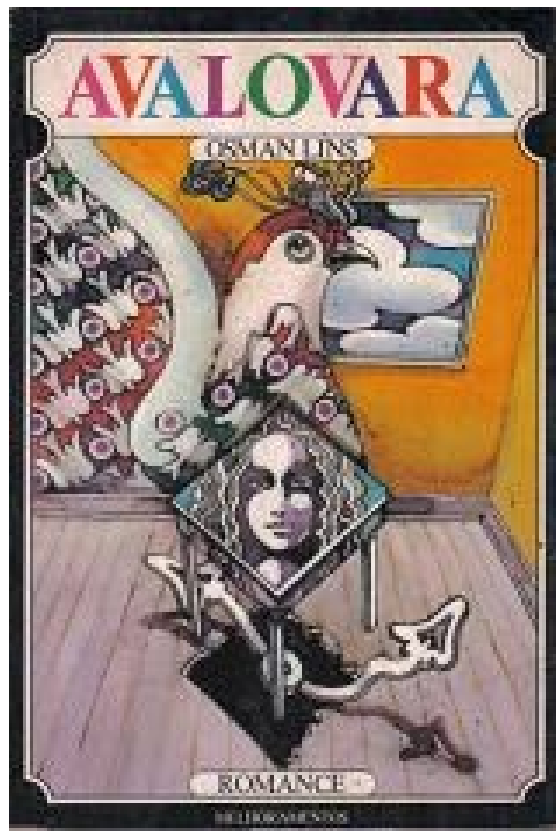

Figura 5 - Capa de Avalovara.

Esta capa, assim como as outras que foram editadas pela Melhoramentos com o mesmo ilustrador, tem elementos montados ao modo surrealista, tais como uma cabeça de pássaro (o Avalovara), os ponteiros tortos de um relógio (uma das linhas narrativas do romance é "O relógio de Julius Heckethorn") embaixo de uma mesa com a cabeça de uma mulher (que poderia ser uma dentre as outras do romance), e as letras coloridas do título sugerindo as diversas linhas do romance. ${ }^{17}$

É nesse sentido que Rockwell Kent, como ilustrador de capas de livros, não ganha a sua fama sem razão. Uma de suas capas famosas é a de Moby Dick, o romance de Herman Melville, mencionado como exemplar das qualidades ilustrativas por Osman Lins em seu artigo do jornal. Menciona inclusive esta edição específica, publicada pela Livraria José Olympio, de 1957, traduzida ao português por Berenice Xavier, com prefácio de Raquel de Queiroz. Por sinal, a edição vem, singularmente, com uma nota sobre as ilustrações, que transcrevo aqui:

Dois artistas colaboram nesta edição de Moby Dick autêntica obra-prima do romance universal: o paranaense POTY, da nova geração artística brasileira, que vem se destacando como um de nossos melhores ilustradores, e o norte-americano ROCKWELL KENT, notável desenhista e renovador da litografia moderna.

\footnotetext{
${ }^{16}$ Ilustrador que permanece incógnito.

${ }^{17}$ ANDRADE, Ana Luiza. Osman Lins: crítica e criação. Curitiba: Appris, 2014.
} 
Os 14 desenhos de POTY trazem a indicação de que são da sua autoria; todos os demais, em numero de 266, são de ROCKWELL KENT, e foram reproduzidas da edição de "The Modern Library", de Random House Inc., Nova Yorque, E.U.A., ed. s/d.. Nossos agradecimentos à grande casa editora pela autorização que nos deu de divulgar no Brasil as ilustrações daquele artista que lhe enriqueceu a bela edição.

Duas das ilustrações de Rockwell Kent para Moby Dick:

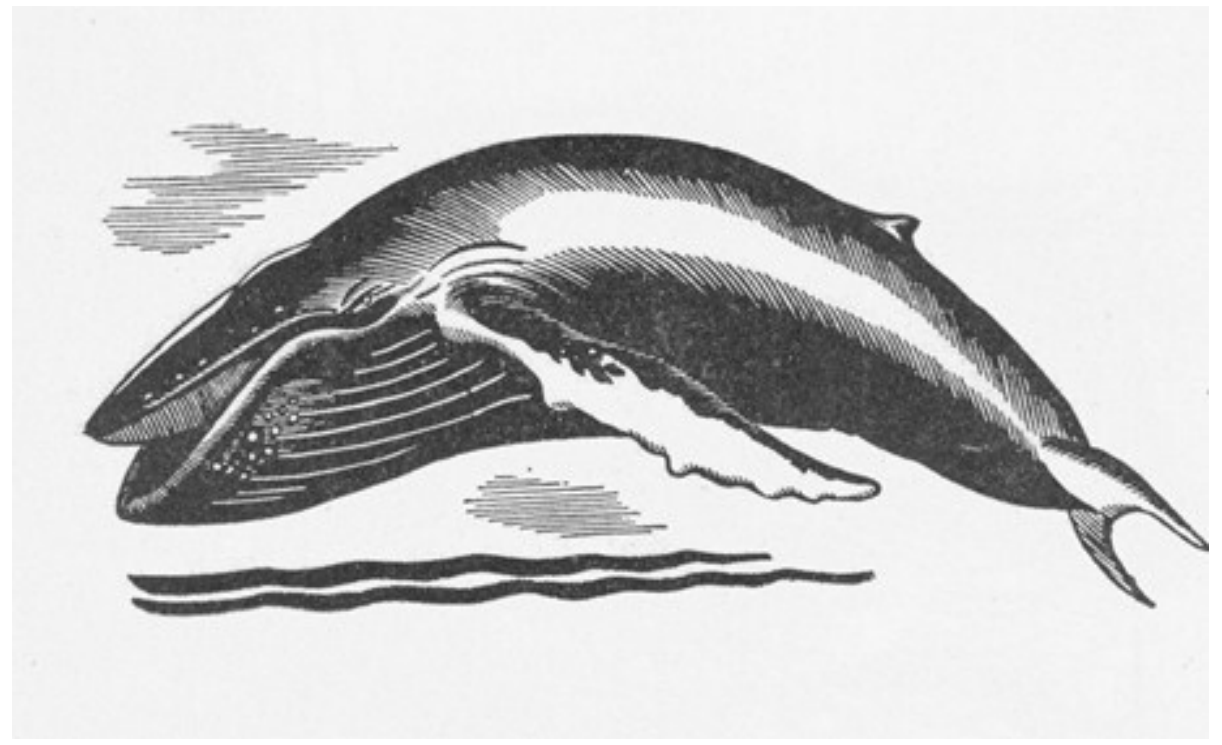

Figura 6 - llustração 1 de Moby Dick, de Rockwell Kent.

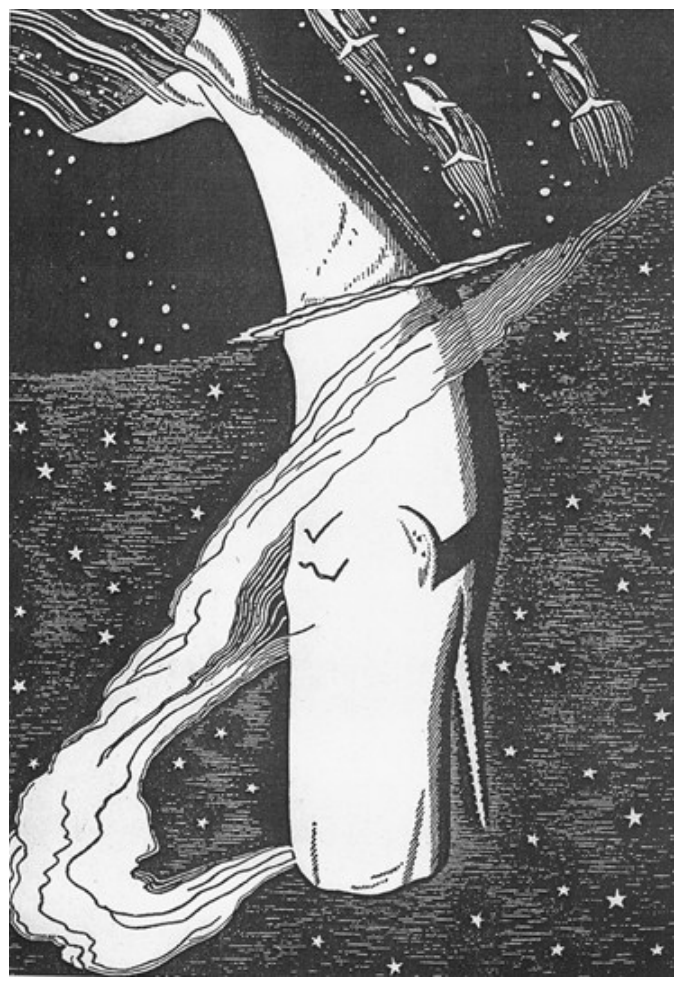

Figura 7 - llustração 2 de Moby Dick, de Rockwell Kent. 
O sucesso das ilustrações romanescas leva-o a criar a série Moby Dick: a porcelana pintada com os motivos do livro de Melville com suas ilustrações:

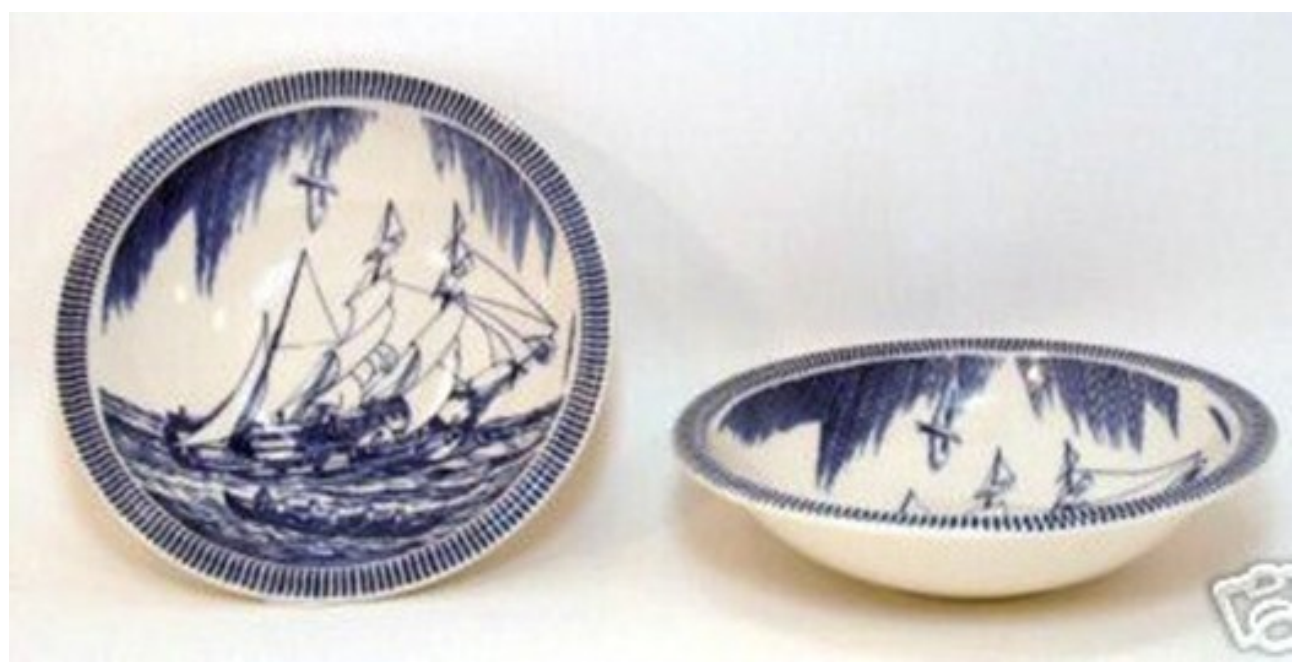

Figura 8 - Série Moby Dick em porcelana.

A série Moby Dick fala da importância que os livros e suas ilustrações ainda tinham na época. Ainda na edição mencionada, em que estes dois ilustradores famosos dividem o espaço das ilustrações, é preciso mostrar o traço definitivamente diferente do desenho de Poty:

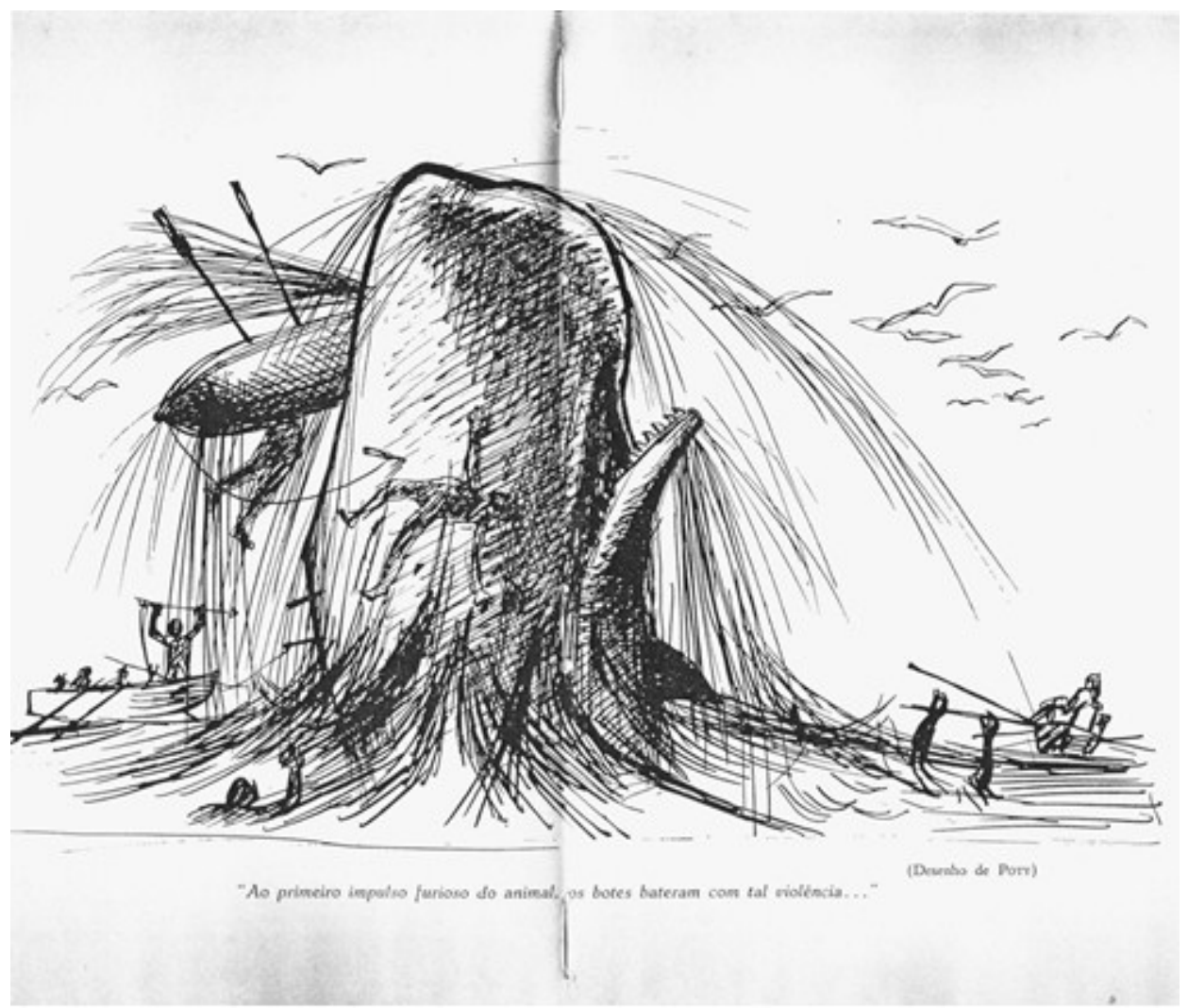

Figura 9 - Ilustração de Moby Dick, de Poty. 
Percebe-se a força do movimento que aparece com os traços finos de Poty contrastando com as ilustrações mais à moda da litografia que caracteriza Rockwell Kent. Osman Lins descreve bem a sensação do leitor destas imagens cheias das palavras do autor do romance, que agora se traduzem nas deste leitor admirador de ilustrações:

\begin{abstract}
Aquelas baleias apocalípticas lançando barcos e homens pelos ares, as visões submarinas e aquelas estrelas que brilham sobre a vastidão do mar como a Estrela de Belém, aqueles pés e mãos de pescador, aqueles instrumentos marítimos ao pé de uma página, as baleeiras açoitadas pelo vento, os homens de aspecto selvagem sobre um mar sem fim, criaturas meditando ao por-do-sol e outras que nos fitam sob um céu que parece o Dia do Juízo, as arcas, as âncoras, as cordas, as correntes, tudo nos envolve com uma força e uma atração terríveis.

E quando a leitura finalmente começa, já não ingressamos num mundo desconhecido. Ainda não fomos apresentados ao Capitão Ahab, desconhecemos Ismael, não encontramos Queequeg, não embarcamos no Pequod.

Mas a amplidão marinha, o tumulto, o mistério, o ímpeto selvagem que vibra naquelas páginas, tudo nos atrai e submete, pois os desenhos de Poty e Rockwell Kent são como um chamado infernal.
\end{abstract}

Deste modo descrito por Osman Lins, as imagens ilustrativas de então se enchiam de palavras, os próprios traços dos ilustradores, gravuristas, desenhistas, servindo como linhas que se teciam entre a palavra e a imagem para formar cenas, imagens fictícias que se por um lado ainda antecipavam a palavra em seus ricos desdobramentos, por outro lado, já anunciavam a imagem cinemática e suas séries industriais.

\title{
REFERÊNCIAS
}

ANDRADE, Ana Luiza. Criação e Crítica. Segunda edição. Curitiba: Appris, 2014.

BENJAMIN, Walter. "O autor como produtor" e "A obra de arte na era da reprodutibilidade técnica". In: Magia e Técnica, Arte e Política. Obras Escolhidas I Tradução: Sergio Paulo Rouanet. Prefácio: Jeanne Marie Gagnebin. São Paulo: Brasiliense, 1994.

LINS, Osman. "Romance e desenho". Jornal do Commercio, 23/agosto/1959.

"Reflexão sobre um livro de contos". Jornal do Commercio, 11/out/1959.

MELVILle, Herman. Moby Dick ou A Baleia. Tradução de Berenice Xavier. Prefácio de Raquel de Queiros. 280 Ilustrações de Rockwell Kent e Poty. Rio de Janeiro: Jose Olympio Editora, 1957.

PHILLIPOV, Karin. Dissertação de mestrado. Rockwell Kent e o Brasil, Orientação de Jorge Coli. UNICAMP, 2008.

ZANINI, Walter. Historia da Arte Geral no Brasil. vol II. Rio de Janeiro: Instituto Moreira Salles, 1983.

LISTA DE ILUSTRAÇÕES

"Percy Lau: um Desenhista e seu Traço". In: Enciclopedia Itaú Cultural. Disponível em: http \: www. enciclopedia.itaucultural.org.br

Ilustradores, Casa de Jorge Amado. Disponível em: www.jorgeamado.com.org

http://finslab.com/enciclopedia/letra-r/rockwell-kent.php

Recebido em 11/05/2015. Aprovado em 16/05/2015. 
Title: Osman Lins and book illustrations, "an infernal call”: images stillyet full of words

Abstract: Living at a time where the publication of industrial series were becoming more and more frequent, Osman Lins, in two of his unpublished chronicles which are brought into light in the present study, calls attention to the transposition of written fiction to the fiction of images. Two of them, which are focused here, "Novel and drawing" (Jornal do Commercio, 23/ago/1959) and "Reflection on a book of short stories" (Jornal do Commercio, 11/out/1959) show, respectively, an uncommon preoccupation by focusing on significant illustrators who publish their drawings in the covers of novels or inside them. Some of them become famous. Such is the case of the Portuguese edition of Herman Melville's Moby Dick and its industrial series. Some of them reflect a rare artistic quality in some of their illustrations. Osman Lins opens up a critical space in the literary criticism of his time, which had the division between image and word very well defined. It never occurred, then, how one could affect the other, or even how one could add or reduce the effects of the other. The same would be true when one thinks of the transpositions which were made from novels to the movies.

Keywords: Osman Lins. Illustrations. Image-word. 